\title{
How to Boost your Business this Summer
}

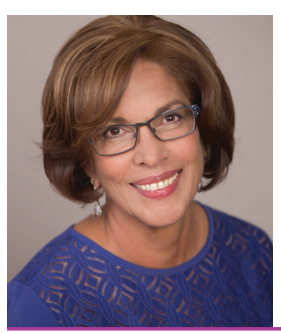

Pauline Blachford

Pauline Blachford consults with optometrists on reducing un-booked appointments, increasing eyewear sales, and improving staff engagement and productivity. She is a sought-after speaker at industry conferences and events, and writes regularly for a variety of industry publications. Visit paulineblachford.com.

$\mathrm{I}^{\mathrm{n}}$

t's easy to relax and take time off in the summer while putting tougher business decisions off until the fall.

As we all begin to plan for long weekends and vacation time, owners should consider how their practices could make the most of the next three months. Summer can be your busiest quarter this year. Here are four ways optometrists can make hay while the sun shines.

\section{ESTABLISH A BUSINESS BASELINE}

Ramping up an often-slower season starts with setting a baseline. Assess the amount of revenue your practice generated through eye exams and eyewear sales from June to August last year. How does it compare to your other quarters, or your busiest?

Repeat this process with data from earlier years to better understand how your summer season typically compares to the rest of your year, and use this as your baseline. If summer sees 15 percent less revenue than other quarters on average, focus on increasing your bookings and sales by that same amount. If your business is relatively steady year-round, set another goal with a different baseline, such as reducing by a certain percentage the number of unbooked appointments your practice sees in an average quarter.

\section{RECALL FAMILIES AND STUDENTS}

Have your re-caller identify patients in your database who are overdue for an eye health exam and who can benefit most from a summer appointment. Summer offers an ideal time to see some of your youngest patients and their parents. This is true too for high school students enjoying time off and post-secondary students who have returned home and may have extended health coverage throughout college or university. Depending on the province, young adults soon turning 18 or 19 years of age are another great market to target before they age out of provincial coverage.

Recalling also provides the chance to have a conversation about your patients' needs, such as sunglasses, products for a new school year that will creep up all too fast and eyewear for summer activities: one of my granddaughters started with prescription swimming goggles at a young age and is now swimming competitively. Convenience, cost-savings and new product options - in addition to the importance of eye health - are points your re-caller should share with patients when asking them to come in.

\section{SUPPORT RECALLING WITH PROMOTIONS}

From discounts on eyewear to rewards for referrals, promotions can help make an optometry appointment too good to refuse or reschedule. These should align with your overall goal this summer: a discount on eyewear products to increase product sales and raise revenue, or a campaign to boost referrals to reduce unbooked appointments.

Get creative with your promotions. A social or client loyalty event can simultaneously boost business and customer satisfaction. One practice I coached in Calgary displayed their sunglasses outside to draw customers indoors. Another gave away Dairy Queen coupons to kids. Partnering with another non-competing local business on a promotion or event is another way to engage and reward customers. ${ }^{1}$

\section{INCENTIVIZE YOUR EMPLOYEES}

There is evidence to back the summer slump. A Harvard Business Review study directly linked sunny days to a decrease in worker productivity and efficiency. ${ }^{2}$ 
You will need the attention, focus and ideas of your employees to implement the ideas above and to handle increased business. One of the best ways to tackle a summer slump is to incentivize your team: research shows team incentive programs with tangible rewards increase performance by as much as 44 percent - double the average increase seen from programs that incentivize individuals. ${ }^{3}$ Include your employees in the success of meeting your summer target. This can include rewards for meeting progress milestones and a final incentive when your goal is ultimately met, such as a team-building excursion, group activity or dinner.

\section{LOOKING AHEAD}

I've previously written in CJO that hiring a locum and cross-training staff can be excellent ways to ensure scheduling does not get in the way of your momentum and productivity. ${ }^{4}$

As we head into my favourite season, remember that a portion of your client base is heading into the biggest block of free time they will have all year. Remember too, that many of your clients can likely benefit from new products to wear during our brightest months. Part of your database may also have optometric benefits through their employer they have yet to use this year.

At the very least, this is a great time to check-in with your patients, update their information, add family members to your database and suggest an appointment if appropriate. At best, doing so gets you a fully booked schedule to carry you through until fall.

\section{REFERENCES}

1. Prendergast C. "8 Marketing Strategies to Help Boost Your Small Business During the Summer Months.” [Entrepreneur website]. Available at: https://www.entrepreneur.com/article/249147. Accessed: March 24, 2019.

2. Lee J, Gino F, Staats B. "Rainmakers: Why Bad Weather Means Good Productivity." July 19, 2002. Available at: http://www.hbs.edu/faculty/ Publication\%20Files/13-005.pdf Accessed: March 24, 2019.

3. Incentives, Motivation and Workplace Performance: Research and Best Practices. [Incentive Research Foundation]. Available at: http://theirf. org/research/incentives-motivation-and-workplace-performance-research-and-best-practices/147/ Accessed: March 24, 2019.

4. Blachford P. Summer Lovin'. CJO 2015;77(1):38 https://opto.ca/sites/default/files/resources/documents/cjo_77-1_summer_loving_-_retention. pdf Accessed: March 24, 2019. 